\title{
PERCORRENDO O RIO NEGRO: INTERDISCIPLINARIDADE ENTRE LITERATURA, HISTÓRIA E GEOGRAFIA NA OBRA DE VERA DO VAL.
}

\author{
Josivaldo Vilaça do Nascimento ${ }^{1}$ \\ Rossemberg da Silva Freitas ${ }^{2}$ \\ Jose Benedito dos Santos ${ }^{3}$
}

\begin{abstract}
RESUMO: O presente artigo tem como objetivo mostrar os resultados do projeto didático intitulado "Percorrendo O Rio Negro: Interdisciplinaridade entre Literatura, História e Geografia Na Obra de Vera do Val", das ministrações de aula da disciplina de estágio supervisionado II com o foco no ensino de literatura e aplicado na Escola Estadual de Tempo Integral Senador Petrônio Portella em uma turma de segundo ano do ensino médio. Utilizou- se como viés teórico os estudos voltados para cada área do conhecimento acima citadas, tais como, Seráfico e Seráfico (2005) e Cândido (2011) e logicamente a riqueza na obra de Vera do Val.
\end{abstract}

PALAVRAS-CHAVE: Literatura Amazonense; Rio Negro; Interdisciplinaridade; História; Geografia.

RESUMEN: El presente artículo tiene como objetivo mostrar los resultados del proyecto didáctico titulado "Recorrer el Río Negro: Interdisciplinariedad entre Literatura, Historia y Geografía en la Obra de Vera del Val", de las ministraciones de clase de la disciplina de práctica supervisada II con el foco en la enseñanza de la literatura y aplicado en la Escuela Estadual de Tiempo Integral Senador Petrônio Portella en una clase de segundo año de la enseñanza media. Se utilizó como sesgo teórico los estudios dirigidos a cada área del conocimiento arriba citados, tales como, Seráfico y Seráfico (2005) y Cândido (2011) y lógicamente la riqueza en la obra de Vera do Val.

PALABRAS CLAVES: Literatura Amazonense; Rio Negro; Interdisciplinariedad; História; Geografia.

\section{INTRODUÇÃO}

A grande árvore da literatura possui em suas várias raízes e ramificações um apanhado de características que permite escolha por parte do autor nos átimos do seu transbordar, tendo em vista que diversos são os motivos que (des) encadeiam à escrita.

Em cada livro escrito há uma biblioteca inteira por trás, pois a primeira paixão do escritor, não foi o ato de escrever, e sim, o de ler. Havendo o conhecimento acerca do universo da literatura, é possível evidenciar que nos vários discursos, quer seja em prosa ou verso, ou em outras formas, há uma gama de informações que permitiram o ato de criação, sendo chamado comumente de conhecimento de mundo.

Exemplos simplórios fazem-se úteis, Augusto dos Anjos carrega sua poesia juntamente com um bisturi, sendo possível notar, portanto, seu grande conhecimento médicos; Victor Hugo,

\footnotetext{
1 Licenciado em Letras- Língua e Literatura Portuguesa pela Universidade Federal do Amazonas. E-mail: josivaldopp16@hotmail.com

${ }^{2}$ Licenciado em Letras- Língua e Literatura Portuguesa pela Universidade Federal do Amazonas

${ }^{3}$ Mestre em Letras - Estudos Literários pelo Programa de Pós-graduação em Letras- PPGL da Universidade Federal do Amazonas. E-mail: profbenesantos@ hotmail.com
} 
em Os Miseráveis, permite que o leitor encontre-se detrás de barricadas, pois é grande seu arcabouço histórico; Graciliano Ramos, por sua vez, em Vidas Seca, exibe o sertão em todas suas rachaduras sulcadas pela geografia.

O que é querido com tais exemplos é a mostra dos possíveis entrelaçamentos da manifestação artística, quaisquer que sejam elas, denotando o envolvimento do artista com o que acontece em sua volta. A interdisciplinaridade encontra nesse liame.

Para este projeto, usar- se- á a obra da contista premiada Vera Do Val, que veio para Manaus em 2002 e foi encantada pelo grandioso Negro, que contribuiu para a escrita de seu mais importante livro, "História do Rio Negro". Nesta obra, é possível encontrar traços que o Amazonas é, de fato, como um Estado envolto por águas, com tantas maravilhas que enchem os olhos de quem vê e de que atua; a vida ribeirinha e o reflexo da Zona Franca; além da relação homem-natureza que é bem retratado pela contista.

De acordo com a Proposta Curricular do Ensino Médio da Secretaria Estadual de Educação do Estado do Amazonas, é no $4^{\circ}$ bimestre do terceiro ano do Ensino médio que os alunos terão contanto com textos e obras de autores da Literatura Amazonense, dentre eles os integrantes do Clube da Madrugada, sendo esse o movimento literário mais marcante que surgiu em 22 de novembro de 1954.

O projeto aqui a ser apresentado teve como público, alunos do $2^{\circ}$ ano do Ensino Médio da Escola Estadual de Tempo Integral Senador Petrônio Portella, objetivando o contato direto com a literatura produzida na região Norte, colocando- os em contato com as histórias ribeirinhas e da cidade no período da instalação e desenvolvimento da Zona Franca de Manaus, mostrando o resgate destas memórias apresentadas por Vera do Val com a aproximação do período em que a cidade de Manaus estava em processo de instalação e desenvolvimento.

O projeto teve como objetivo geral buscar, por meio da literatura regional, a interdisciplinaridade entre a geografia e história, a utilidade que o estudo de tais disciplinas pode ter na compreensão e na reflexão acerca do espaço do qual o aluno faz parte, de maneira a permitir a integração entre disciplinas, aprofundamento da socialização dos alunos e contextualização dos conhecimentos adquiridos em sala de aula.

E como objetivos específicos, fazer com que os alunos analisassem o papel da Zona Franca de Manaus no desenvolvimento das histórias; o "lugar" do ribeirinho na sociedade; junto 
com os professores do estágio, buscassem exemplos de relações entre seres e o ambiente, em suas delimitações geográficas e possibilidades de interação com o espaço, estabelecendo um paralelo entre as relações sociais apresentadas no livro e a comunidade em que os alunos vivem.

\section{A PROBLEMÁTICA}

1. Será que os alunos do $3^{\circ}$ ano possuem alguma ideia da Literatura produzida em sua região?

Fora proposto aos alunos a meta de estabelecer um paralelo entre as relações sociais apresentadas no livro e o ambiente em que vivem. Uma vez que as obras de literatura amazonense possui grande representatividade, mas pouco conhecimento em sua própria região. Sendo assim, essa proposição se fez necessária para que possamos averiguar se os alunos possuíam algum tipo de imagem acerca da literatura amazonense.

Para que o projeto seja correspondido de maneira eficaz, foram traçadas algumas questões a serem vistas ao longo das aulas e a serem respondidas no final das ministrações das mesmas.

2. Os alunos conseguem buscar exemplos de relações entre seres e meio ambiente, em suas delimitações geográficas e possibilidades de interação com o espaço?

Os contos foram utilizados como base para que os alunos possam refletir acerca da relação entre o ser humano e o ambiente e em sua complementação mútua ao longo da obra.

3. Dentro de uma visão capitalista, qual será o lugar do ribeirinho na sociedade, os alunos podem chegar a reflexões por meio dos contos da Vera do Val?

Foi proposto uma reflexão atual e histórica do papel do ribeirinho na sociedade e como ele é visto atualmente e quais os resquícios presentes no conhecimento dos alunos.

\section{QUESTÃO TEÓRICA}

HISTÓRIA

Segundo Seráfico e Seráfico (2005) “a criação da Zona Franca de Manaus foi justificada pela ditadura militar com a necessidade de se ocupar uma região despovoada". Para a ditadura militar, a criação da zona franca de Manaus tinha como objetivo ocupar um lugar que, segundo eles, não era povoado, mas essa ideia fez-se errônea, afinal, já havia pessoas ocupando tal espaço, histórias sendo construídas e gerações surgindo. É nesse contexto que a Operação Amazônia, de que a Zona Franca de Manaus é um capítulo, adquire sentido.

O desenvolvimento capitalista na região amazônica foi o foco do militarismo e desprendimento das outras forcas econômicas, assim, seria preparação da região para o mundo. 
A operação de tornar a Amazônia um lugar propício para que outras atividades capitalistas se instalassem.

\section{GEOGRAFIA}

A segregação espacial e urbana acontece onde há uma grande diferença de renda de grupos familiares, ou seja, os que possuem mais condições de ter uma moradia cara ficam em uma área da cidade, com vários outros benefícios, diferentemente de outras famílias que não possuem as mesmas condições e exilam-se em áreas mais afastadas. Essa segregação concentra as famílias de classes sociais em diferentes regiões ou bairros da cidade.

No Amazonas encontramos exemplos de cidades afastadas da capital que possuem menos habitantes e menos condições financeiras, e por isso, mantêm-se as margens dos rios, retirando seu sustento da pesca ou da mão de obra dos próprios habitantes da região.

\section{LITERATURA}

Antônio Cândido chama de literatura,

da maneira mais ampla possível, todas as criações de toque poético, ficcional ou dramático em todos os níveis de uma sociedade, em todos os tipos de cultura, desde o que chamamos folclore, lenda, chiste, até as formas mais complexas e difíceis da produção escrita das grandes civilizações. (CANDIDO, 2011, p. 174).

Assim, Vera do Val ganha destaque, por ser a escritora de uma obra literária que une o misticismo, que há no Amazonas, juntamente com uma comunidade composta por pessoas, por ribeirinhos que encontram no Rio Negro, não só sustento ou prazer, mas uma extensão da alma.

Vera traz meninas que tornam- se mulheres com o florescer da idade, mulheres que vêem em si algum traço da mocidade ingênua. Mães, adolescentes, prostitutas, maridos, esposas, e tantos outros que fazem da margem do rio seu cenário de cada dia.

A literatura amazonense teve seu principal destaque com o movimento literário Clube da Madrugada e figuraram como fundadores os escritores Farias de Carvalho, Saul Benchimol, Luiz Barcellar, Francisco Batista, João Bosco Araújo, Fernando Collyer, Humberto Paiva e Camilo Souza. Jorge Tufic ressalta o papel do Clube com os seguintes dizeres: "Escolhendo por 
sede a praça do Ginásio, o Clube gerou uma atmosfera de pesquisa e criatividade, sem precedentes na história de uma sociedade comum. Seu estatuto foi mera formalidade para tornar-se de utilidade pública. Deste modo, fazendo-lhe a paráfrase satírica, tentamos recolocalo em sua verdadeira órbita no Estatuto do Vigésimo ano, publicado no Jornal do Comércio de 31/ 03/ 74.” (TUFIC, Sem ano).

\section{PROCEDIMENTOS DIDÁTICOS}

Na primeira aula, preparou-se uma apresentação aos alunos com o intuito de evocarlhes o interesse e a curiosidade ao que será trabalhado, a fim de prender sua atenção, e posteriormente, proporcionar a grande responsabilidade da escola que é formar cidadãos, possuindo a literatura como forma capaz de fruir e instruir o ser humano. Assim faremos aos alunos, ao mostrar-lhes o retrato poético que Vera do Val traz em seu livro Histórias do Rio Negro.

Iniciou-se com a própria Introdução do livro, a mostrar que o Rio Negro não é mero cenário, é personagem que habita em todo o universo presente no livro, e explicar com bases na Geografia e na História do Amazonas que o mesmo ocorre na realidade ribeirinha, e mesmo a citadina, pois o manauara que mora no centro da cidade também deslumbra da visão do Rio e é por ele encantado. O Rio Negro tem sentimentos e beleza sem igual, "é a gênese da Manaus e da vida".

$\mathrm{Na}$ segunda regência foi abordado o conto "Rosalva" e após a leitura completa do conto, uma breve explicação acerca do seu contexto no livro, além de abrir espaço para a impressão por parte dos alunos. Os mesmos tiveram que identificar a temática dos textos, ao ouvir o título do conto e tendo em mente o título do livro. Este primeiro contato com as histórias de Vera do Val foi crucial para o andamento do projeto, pois a partir desta experiência que víamos como os alunos estavam acompanhando o raciocínio proposto ao projeto.

Ao saberem a temática do livro, partiu-se para localização de informações implícitas e explícitas, levantamentos feitos pelos próprios alunos que foram motivados a indagar sobre o que traz Vera do Val, com o intuito de mostrar o Amazonas com o olhar de Vera do Val. No conto, a personagem entra em comunhão com o Rio Negro, que encontra fim nos braços do rio.

$\mathrm{Na}$ terceira ministração de aula, foi abordado o conto "Giselle" para que os alunos pudessem perceber o impacto da instalação da Zona Franca, sendo a Amazônia um lugar propício para que outras atividades capitalistas se instalassem, tais como as atividades como 
doméstica e parteira que são abordadas no livro.

Para que os alunos situassem- se ainda mais no universo amazônico descrito por Vera do Val, foi pedido que eles buscassem outros textos literários em que fosse possível discorrer acerca da relação do homem com a natureza. Toda discussão serviu de contribuição para a história que deverá estar em fase de finalização.

Durante as aulas, um apanhado de imagens foram passadas em apresentação PowerPoint, para que os alunos visualizassem e criassem, a partir do que fora visto, a história em questão, além de interpretarem os textos com o auxílio do material visual e identificarem a finalidade dos contos. Ainda nas duas primeiras aulas, foi exposto o que se esperava como produto final.

$\mathrm{Na}$ quarta aula foram abordados os aspectos teóricos de um conto, tais como sua característica e identificação de o que é um conto, para que os alunos conseguissem assimilar e conectar ao que já havia sido abordado nas aulas anteriores e assim não utilizar o texto somente como pretexto para ser lido ou ministrado um conteúdo vago. Assim, ao fim da explicação, foram sanadas as dúvidas que apareceram, dado início, portanto, ao desenvolvimento do produto final.

A quinta aula deu-se de indagações, questionamentos acerca dos assuntos abordados durante as aulas, e uma breve explicação da ligação entre as disciplinas tomadas como base para o projeto, com o intuito de mostrar ao aluno que é possível compreender um todo, partindo de que não é somente um enquadramento imposto a uma matéria. E por fim, as apresentações dos contos que foram produzidos.

\section{O PROCESSO AVALIATIVO E OS RESULTADOS FINAIS}

Ao fim dos contos lidos de Histórias do rio Negro, solicitou-se dos alunos que produzissem um pequeno parágrafo com questões observadas nos textos que lhes pareceram interessantes. Foram realizadas discussões acerca das questões destacadas para finalizar o ciclo de contos lidos durante a semana, de natureza cultural (o imaginário das comunidades ribeirinhas, seus costumes), social (o contexto dessas comunidades, as relações interpessoais e personagens alegóricos), além do contato com a natureza, presente na obra de Vera do Val, procurando sempre entender como tais questões influenciam umas às outras. Ao fim, os alunos produziram uma pequena narrativa semelhante às de Vera do Val, mas utilizando elementos de sua própria vizinhança, comunidade, família, expondo no texto sua própria perspectiva acerca 
do espaço que habita.

Durante as ministrações de aulas, os alunos mostravam-se interessados nos textos de Vera do Val e buscavam ao máximo a participação durante as aulas.

No primeiro dia, logo na apresentação que iria ser tratado, os alunos assumiram que pouco ou até mesmo nunca haviam tido contato com alguma obra de literatura amazonense, mesmo a maioria sendo residente da região norte, assim, por meio das indagações por nós feitas, essa maioria também expos que a maioria de suas leituras e que tinham conhecimento era de obras estrangeiras e que mais estão na "moda" nos permitindo explorar ao máximo a obra de Vera do Val e mostrar um universo inédito aos alunos do segundo ano do ensino médio.

Durante a primeira aula ao se depararem com o título da obra e do capítulo, foram questionados sobre o que esperavam encontrar no corpo da obra, os mais diversos temas foram ditos, principalmente em que os alunos viam o Rio Negro apenas como parte do meio ambiente e ao explicarmos que o rio seria o personagem principal da obra e não apenas o lugar onde a obra seria tratada os alunos ficaram atentos a leitura da introdução.

O professor supervisor em específicos momentos relembravam os alunos sobre aspectos já vistos e comentados na aula dele, mostrando o entrelace que a obra faz suas aulas.

Ao entregarem suas avaliações escritas, foi percebido que dos 30 alunos em sala de aula, 25 conseguiram assimilar o papel do Rio Negro na obra, no sentido que perceber a imagem do Rio Negro como sendo além de meramente um montante de água escura que serve como ponto de encontro e turístico na cidade de Manaus. Tendo ideia disto, como a maioria buscou compreender o sentido de personificação do rio, deu-se a indagação do próprio discente em conhecer os tais percursos do rio que é mencionado mo título do projeto e assim, podendo deixar em aberto a utilização dos contos selecionados para as ministrações.

No segundo e no terceiro dia de aula os alunos conseguiram com êxito realizar as leituras dos contos "Rosalva" e "Giselle", sempre mostrando um bom desenvolvimento, até mesmo com palavras de teor mais sensual e que fazia com que as turmas formassem pequenos momentos de conversas avulsas. Nas salas de aula, ao passar do tempo, foram colocadas barreiras em relação aos conteúdos de teor mais sensual, já que ainda é visto como um tabu a utilização da sensualidade e da sexualidade em contos, tendo em vista que o mundo, esse espaço que não que não há limites para o processo de aprendizagem e descoberta, principalmente para adolescentes, então, a utilização da obra de Vera do Val, contribuiu também para que os alunos mesmo em meio às reações "envergonhadas" dos alunos mostrar o lado sensual de forma mais misteriosa e bela. 
Para os alunos do ensino médio que somente se deparam com as obras de literatura brasileira de outros estados e períodos literários que são propostos apenas com o intuito de pretexto para uma leitura obrigatória e até mesmo cansativa que não desperta o interesse do aluno em buscar outros ramos que as obras apresentam e esse também foi um dos objetivos que foram conseguidos, mostrar aos alunos que a obra de Vera do Val possui relação com outras disciplinas, tais como a história e a geografia por meio da interdisciplinaridade.

Como produto final foi solicitado que os alunos construíssem um conto baseado nos contos maravilhosos, por exemplo, os contos de Chapeuzinho Vermelho, Rapunzel, Cinderela e até mesmo um conto de autoria "original”, permitindo que eles colocassem na prática o que já haviam visto durante as aulas de estágio e exercitando também a escrita dos mesmos.

A disciplina visa à observação e ministração de aulas em escolas da rede pública e/ou particular em nível de $1^{\mathrm{a}}$ a $3^{\mathrm{a}}$ séries do ensino. Entre as atividades da disciplina, foram elaboradas um total de 5 (cinco) aulas por série, regidas por diferentes professores e, se possível, diferentes escolas. Relatar, discutir e avaliar os resultados das observações feitas à luz dos preceitos teóricos e práticos estudados durante o curso e por fim apresentar relatório final escrito em forma de memorial.

O Estágio Curricular II teve como finalidade mostrar os resultados do projeto didático intitulado: "Percorrendo O Rio Negro: Interdisciplinaridade entre Literatura, História e Geografia Na Obra De Vera Do Val", entre as atividades das ministrações de aula na disciplina de estágio supervisionado II, tivemos como foco o ensino de literatura e sua aplicação na Escola Estadual de Tempo Integral Senador Petrônio Portella na turma do $2^{\circ}$ ano do ensino médio com a duração de 5 aulas planejadas previamente e executadas por meio dos planos de aula.

De acordo com a Proposta Curricular do Ensino Médio da Secretaria Estadual de Educação do Estado do Amazonas no $4^{\circ}$ bimestre do Ensino médio é somente quando os alunos terão contanto com textos e obras de autores da Literatura Amazonense, dentre eles são listados os integrantes do Clube da Madrugada, porém, questionamos: Será que os alunos realmente conseguem chegar a leituras das obras que são produzidas em ambiente regional, afinal, muitas obras das grandes escolas literárias se passam nas grandes metrópoles como o Rio de Janeiro?

O projeto teve como objetivo geral buscar por meio da literatura regional a interdisciplinaridade entre a geografia e história, a utilidade que o estudo de tais disciplinas pode ter na compreensão e a reflexão acerca do espaço do qual o aluno faz parte de maneira a permitir a integração entre disciplinas, aprofundamento da socialização dos alunos e contextualização dos conhecimentos adquiridos em sala de aula. 
E como objetivos específicos, fazer com que os alunos analisassem o papel da Zona Franca de Manaus no desenvolvimento das histórias; o "lugar" do ribeirinho na sociedade; buscassem, junto com os professores do estágio, exemplos de relações entre seres e o ambiente, em suas delimitações geográficas e possibilidades de interação com o espaço, estabelecer um paralelo entre as relações sociais apresentadas no livro e a comunidade em que os alunos vivem.

Após a realização e finalização das ministrações, pudemos constatar que os alunos do ensino médio da escola, pouco possuíam conhecimento sobre obras que haviam sido produzidas no Estado do Amazonas e se conheciam algum autor amazonense. O professor da classe e os alunos foram receptivos e atenciosos nas aulas, buscavam participar dos diálogos e assim os orientava, para que pudessem contribuir com o entendimento da obra.

O aprendizado é aperfeiçoado nas escolas, por meio das aulas práticas dos professores, que são, na maioria das vezes, os maiores formadores de opiniões. Não precisamos como docentes dar conceitos prontos, mas sim levar o aluno à reflexão para que o mesmo possa chegar a um conceito, uma opinião formada sobre os assuntos norteadores na sociedade.

\section{REFERÊNCIAS}

CANDIDO, Antônio. Vários escritos. Rio de Janeiro: Ouro sobre azul, $5^{\mathrm{a}}$ ed., 2011.

CANDIDO, Antônio. Literatura e Sociedade. Rio de Janeiro: Ouro sobre Azul, 11ª ed. 2010.

FREDICO, EnidYatsuda; OSAKABE, Haquira. Literatura. http://portal.mec.gov.br/seb/arquivos/pdf/03Literatura.pdf. Acessado em 30/11/2017, às 18:50.

Secretaria de Educação Fundamental. Parâmetros curriculares nacionais: terceiro e quarto ciclos: apresentação dos temas transversais. Brasília: MEC/SEF, 1998.

SERÁFICO, José; SERÁFICO, Marcelo. A Zona Franca de Manaus e o capitalismo no Brasil. DOSSIÊ AMAZÔNIA BRASILEIRA II. Estud. av. vol.19 n54, São Paulo May/Aug. 2005. Disponível em <http://www.scielo.br/scielo.php?script=sci_arttext\&pid=S0103$40142005000200006>$

Acesso em 31/11/2017.

TUFIC, Jorge. Existe uma literatura Amazonense?

VAL, Vera do. Histórias do rio Negro. Manaus: Edições Muiraquitã, 2011. 